TITLE:

\title{
Institutional diffusion for the Minamata Convention on Mercury
}

\author{
AUTHOR(S): \\ Uji, Azusa
}

\section{CITATION:}

Uji, Azusa. Institutional diffusion for the Minamata Convention on Mercury. International Environmental Agreements: Politics, Law and Economics 2019, 19(2): 169-185

\section{ISSUE DATE:}

2019-04

URL:

http://hdl.handle.net/2433/241769

\section{RIGHT:}

This is a post-peer-review, pre-copyedit version of an article published in 'International Environmental Agreements: Politics, Law and Economics'. The final authenticated version is available online at: https://doi.org/10.1007/s10784-01909432-z:; The full-text file will be made open to the public on 25 February 2020 in accordance with publisher's 'Terms and Conditions for Self-Archiving'.; この論文は出版社版でありません。引用の際には出版社版をご確認ご利用ください

。; This is not the published version. Please cite only the published version. 


\title{
Institutional Diffusion for the Minamata Convention on Mercury
}

\author{
Azusa Uji \\ Graduate School of Government, Kyoto University \\ Yoshida Honmachi, Sakyo-ku, Kyoto 606-8501 JAPAN \\ Email: uji.azusa.54r@kyoto-u.jp \\ ORCID: 0000-0001-9992-5908
}

\begin{abstract}
A trinity composed of legally binding regulations, an independent financial mechanism, and a compliance mechanism characterizes the institutional design of the Minamata Convention on Mercury. Meanwhile, few existing environmental treaties feature an independent financial mechanism as well as a compliance mechanism. Why did the Minamata Convention acquire two mechanisms? There are two rival hypotheses on uncertainty about institutional consequences and international agreements. The rational design school posits that countries can predict institutional consequences by acquiring all pieces of relevant information (Koremenos et al. 2001) and views the trinity as a rational design to enhance developing countries' regulatory capabilities under strict compliance. In contrast, the institutional diffusion school assumes that countries have limited information-processing abilities and use cognitive heuristics in designing institutions and argues that countries designed the trinity by learning from existing cases (Ovodenko and Keohane 2012). In this paper, I compare the negotiations process of the Minamata Convention with that of the Stockholm Convention on Persistent Organic Pollutants (POPs). To test the hypotheses, I examine how countries resolved informational uncertainty in both negotiations by utilizing negotiations records and personal interviews with key officials as data. The analytical results support the institutional diffusion hypothesis by indicating that the trinity within the Minamata Convention is a product of countries' heuristic and incremental learning from existing treaties.

Keywords: environmental treaty, Minamata Convention on Mercury, institutional design, negotiations, learning, UNEP

Acknowledgments: This research was made possible by grants from the Japanese Society for the Promotion of Science (\# 26245020), the Konosuke Matsushita Memorial Foundation (\#15-205), and the Sompo Japan Nipponkoa Environmental Foundation. An earlier version of this manuscript was presented at the 58th ISA Annual Convention in Baltimore and the 59th ISA Annual Convention in San Francisco. I am most thankful to Motoshi Suzuki for constructive and critical comments throughout this research. I thank Ronald Mitchell, Henrik Selin, Oran Young, Pam Chasek, Maria Ivanova, Stacy Vandeveer, Takahiro Yamada, and Satoshi Miura for their invaluable comments. I wish to thank my interviewees for their insights about the negotiations on the Minamata Convention and the organization of the UNEP.

Compliance with ethical standards: The author declares no conflicts of interest.
\end{abstract}




\section{Introduction}

Under what circumstances do countries agree on a set of institutions that can effectively solve environmental problems? The Minamata Convention on Mercury (hereafter the MC), a treaty aimed at regulating mercury, entails a unique institutional arrangement characterized by a "trinity" comprising (1) legally binding emissions regulations, (2) an independent financial mechanism for capacity building, and (3) a compliance mechanism with monitoring and evaluation. ${ }^{1}$ This trinity is expected to function coherently to enhance the treaty's effectiveness. However, institutions featuring all three mechanisms have rarely been established historically.

The MC is the first treaty within which the three institutions mentioned above were created upon the conclusion of the treaty negotiations. Among existing environmental treaties, the Montreal Protocol on Substances that Deplete the Ozone Layer (hereafter the MP) is another treaty including all three institutions, although two (the mechanisms of independent finance and compliance) were incorporated into the protocol several years after it took effect. A critical political dynamic should have been operating behind the simultaneous establishment of two institutions for the MC. Thus, this paper explores the political background that helped to create these institutions, ensuring compliance by focusing on the MC.

The paper presumes that informational uncertainty regarding institutional consequences hinders the formation of agreements. There are two rival hypotheses on how countries deal with such uncertainty. The rational design school posits that countries can predict institutional consequences by acquiring all pieces of relevant information (Koremenos et al. 2001) and views the trinity as a rational design for enhancing developing countries' regulatory capabilities under strict compliance. In contrast, the institutional diffusion school assumes that countries have limited information-processing abilities and use cognitive heuristics to design institutions; furthermore, this school argues that countries designed the trinity by learning from existing cases (Ovodenko and Keohane 2012). In this paper, I compare the MC with the 2001 Stockholm Convention on Persistent Organic Pollutants (POPs) (hereafter the SC), which failed to establish such a trinity. To test these hypotheses, I analyze the degree of distributional problems and how countries resolved informational uncertainty in each negotiation process. The analytical results support the institutional diffusion hypothesis by indicating that the MC trinity is a product of heuristic and incremental learning from existing treaties. For the $\mathrm{MC}$, treaty experience was accumulated over a decade and effectively processed by negotiators to reduce uncertainty. Learning from experience, negotiators successfully evaluated institutional consequences more accurately.

The paper is structured as follows. Section 2 describes the trinity's functions in relation to compliance and evaluates existing studies on the MC's institutional design. Section 3 proposes a theoretical and methodological approach for the analysis in Section 4. The final part summarizes the findings and offers implications for the literature.

\section{2. "Institutional Trinity"}

\footnotetext{
${ }^{1}$ In this paper, multilateral environmental agreements (MEAs) are conceptualized as "environmental treaties." Meanwhile, "institutions" indicate specific mechanisms (e.g., financial and compliance mechanisms) created within treaties. "Institutional design" indicates how treaties are structured.
} 
Legally binding rules have an advantage in ensuring deep cooperation over non-binding rules. Nonetheless, a legally binding treaty might discourage countries from participating in it more strongly than a non-binding treaty. This is because countries with low capacities encounter higher compliance costs in participating in the former than in the latter. Thus, a major challenge in guaranteeing universal treaty participation is reducing compliance costs for low-capacity countries so that they can accept high-level commitments. Here, a financial provision is employed that lowers compliance costs to prevent non-compliance ascribed to insufficient capacity (Mitchell 2007: 915). However, in many environmental treaties, the causes of non-compliance are not well considered in financial allocation, and financial provision fails to correct noncompliance. This is because a financial mechanism is not associated with an information system, such as a compliance mechanism, that monitors parties' compliance status (Mitchell 2007: 915916). Therefore, financial aid is provided ineffectively without "knowing how the actors behaved with respect to the agreement's proscriptions or prescriptions" (Mitchell 2007: 916). This is why financial aid is not appropriately allocated to correct non-compliant behaviors. Such a shortcoming in a financial provision generates mutual suspicion between developed and developing countries: the former suspect that financial provisions are ineffective and then request they be more cost-efficient. In light of the increasing emphasis on cost efficiency, developing countries have recently criticized the Global Environmental Facility's (GEF) financial allocation procedure, which align with developed countries' political interests rather than with the capacitybuilding needs of developing countries (Marcoux et al. 2011: 35; Streck 2001).

An effective way to overcome the problem is to combine an independent financial mechanism with a compliance mechanism. The MP provides a good example for this integrative approach. A compliance mechanism, distinguished from a reporting or implementation system, is the most advanced mechanism to ensure compliance; when administered by a committee under the aegis of the Conference of the Parties (COP; a treaty's governing body), such a mechanism can identify non-compliance, determine its underlying causes, and ensure compliance through appropriate capacity-building measures (Raustiala 2001: 9-14). Equally important, a compliance mechanism performs effectively with a proper financial mechanism (De Chazournes 2006). For example, an independent fund like the Multilateral Fund (MLF), internalized within the MP (rather than the GEF as an external organization), was easily incorporated into a compliance mechanism insofar as both mechanisms operate under the COP. Under the protocol, monitoring by a compliance committee has helped to allocate multilateral funds appropriately to address non-compliance causes (Victor 1999). This ensures that most countries view alternative actions as more attractive than their existing non-compliant behaviors, which are not achieved with financial provisions under many environmental treaties (Mitchell 2007: 916). Therefore, the integrative mechanisms combining compliance and independent finance can enhance compliance with legally binding commitments (Brunnée 2006; De Chazournes 2006; Victor 1999). This has recently been recognized among the scholars and practitioners who observed major progress in the effectiveness of the MP. The Principal Coordinator of the Interim Secretariat of the Minamata Convention on Mercury also views the MC as "ambitious" as it entails a set of institutions to ensure high levels of compliance. ${ }^{2}$

\footnotetext{
${ }^{2}$ The author's interview with the Principal Coordinator of the Interim Secretariat of the Minamata Convention on Mercury took place on June 29, 2017.
} 
Similarly, based on interviews with stakeholders, Templeton and Kohler (2014) argued that the treaty established a compliance mechanism because (1) inter-linkage with a financial mechanism and (2) intellectual or entrepreneurial leadership by the chairs enabled the parties to agree to establish a compliance mechanism. Templeton and Kohler's analysis (2014), which encompasses both financial and compliance mechanisms, is close to my attempt at explaining a trinity. However, they did not conduct a comparative analysis and could not account for why the MC created both an independent fund and a compliance mechanism but similar chemicals treaties did not. In fact, the mercury negotiations are not the first case in which both financial and compliance mechanisms were discussed as important agendas. ${ }^{3}$ Below, I provide a detailed examination of the issue linkage between financial and compliance mechanisms that led to the foundation of a trinity in the MC. ${ }^{4}$

\section{Theory and Methodology}

\subsection{Theory}

In designing a treaty to solve environmental problems, countries should reduce uncertainty regarding the consequences of the institutions that they establish within the treaty. The rational design school views a treaty as a rational construct for solving environmental problems in accordance with issue-specific factors such as issue visibility, the interest structure, and regulatory costs (Abbott and Snidal 2000; Koremenos et al. 2001; Mitchell 1994; Mitchell and Keilbach 2001). This school assumes that treaty negotiators can resolve informational uncertainty about institutional consequences. It posits that countries facing uncertainty can predict outcomes of institutional choices correctly and solve issue-specific problems by determining a variety of institutional mechanisms, including the size of membership, the scope of issues, the degree of centralization, and the strength of regulatory control.

In contrast, the institutional diffusion school takes informational uncertainty more seriously. It assumes that informational scarcity is prevalent, which largely influences institutional design through negotiations (Ovodenko and Keohane 2012: 523). Thompson (2010: 274-275) argues that uncertainty is high if multiple institutional solutions to a problem exist, thus prompting countries to have conflicting views on which solution is best. Furthermore, such uncertainty would be generally high in the initial stages of treaty-making because negotiators rarely share $e x$ ante sufficient technical, legal, and scientific knowledge to predict and evaluate the outcomes of institutional choices. This school considers that institutions are transferred from one treaty to another via cognitive heuristics and incremental learning. This idea originated with organizational theorists in the 1950s. Alchian (1950) maintains that organizations typically lack relevant information and skills to perform maximizing calculations; Simon (1957: 198) asserts that this is because "the size of the problems... requir[ing] objectively rational behavior" is broader than the mind's complex problem-solving capacity. Faced with uncertainty, organizations generalize from a handful of proximate examples and imitate them inappropriately (Weyland 2005: 284-286; Marsh and Sharman 2009: 282). They rely on cognitive heuristics and incremental learning, which are distinct from rational learning. Nonetheless, information accumulates incrementally through the discovery of new information (Boerner et al. 2001: 92), which organizations

\footnotetext{
${ }^{3}$ See Note 2.

${ }^{4}$ For detailed institutional analyses of the MC, see Andresen et al. (2013), Selin (2014), Eriksen and Perrez (2014), Stokes et al. (2016), and Sun (2017).
} 
incorporate into their prior knowledge through slow updating. They may also take wrong cues from the policy experiences of others or a wrong-headed theory (Simmons et al. 2006: 795-797).

In the context of environmental treaties, Ovodenko and Keohane (2012: 523) maintain that "[f]or governments seeking information about the likely consequences of specific institutional designs, existing institutions are natural sources of information." They provide a model of "mimetic diffusion" within which parties adopt successful treaty institutions for similar environmental problems, which in turn can provide focal points for resolving informational uncertainty (Ovodenko and Keohane 2012: 534). Additionally, they argue that international organizations, such as the United Nations Environment Programme (UNEP), assist countries in mimetic diffusion and the institutionalization of treaties by acquiring knowledge on specific types of environmental problems and particular cases of institutional development. While they recognize the role of international organization and the intervening effect of state interests and power on diffusion, they do not fully incorporate negotiations into their analysis (Ovodenko and Keohane 2012: 538-539).

Informational uncertainty, however, is not the only factor that accounts for a trinity. One might attribute the presence or absence of the trinity to the feasibility of an agreement. Mitchell and Keilbach (2001: 894-896) and Mitchell (2010: 113-122) contend that a determinant of agreement is the severity of a distributional problem in terms of how to allocate regulatory costs and benefits among the parties involved. However, if distributional outcomes arising from the treaty between them are excessively divergent, or if a distributional problem is severe, countries face substantial difficulty in agreeing on a treaty (Ovodenko and Keohane 2012: 534-535). By contrast, if a distributional problem is moderate, informational uncertainty matters in reaching a trinity.

These rival arguments suggest the following hypotheses ${ }^{5}$ :

H1: If a distributional problem is moderate, negotiators can agree on a trinity because negotiators are a priori rational and capable of processing all relevant information for institution building. $\mathrm{H} 2$ : If a distributional problem is moderate, negotiators can only agree on a trinity when they have acquired abundant informational sources to learn about institutional consequences through incremental learning.

\subsection{Methodology}

To evaluate these hypotheses, I analyze the Minamata and Stockholm Conventions for the following reasons. First, both the SC (2004) and the MC (2013) entered into force after 2000. Second, both treaties have similar goals of protecting human health and the environment from toxic chemicals that remain intact in the environment for long periods. Due to regulatory similarity, countries initially attempted to incorporate a "mercury protocol" of regulations into the SC (UNEP 2007: 61-65). However, they decided against this because a treaty covering both POPs and mercury would provide laxer regulation of mercury than a treaty solely focusing on regulating mercury (Selin and Selin 2006: 266).

Despite these similarities, neither an independent fund nor a compliance mechanism was established in the SC as was in the MC (see Section 4-1). The SC created the GEF as an interim

\footnotetext{
${ }^{5}$ In this article, I evaluate the empirical validity of these hypotheses by assuming that negotiators are rational with high information processing abilities.
} 
financial mechanism and an enabling clause stipulating that the parties put into place a compliance mechanism in future COP meetings. Such a mechanism, however, was never agreed upon in following COPs. I analyze below the extent of the distributional problems and informational uncertainty in both conventions to determine what factors differentiated their respective institutional designs. More specifically, I explore how countries dealt with uncertainty and agreed on an independent fund and a compliance mechanism in the Minamata negotiations. The subsequent analysis weighs more on the mercury negotiations rather than the POPs negotiations, owing to my main focus on the MC.

To evaluate my hypotheses, I adopt the following steps in examining two plausible explanatory variables that could differentiate institutional designs between the two conventions. First, I compare the two conventions regarding the degree of distributional problems. I measure the intensity of the distributional problems using issue-specific factors including issue visibility, the obligations of developed and developing countries, and the technological and economic costs of regulations (Mitchell 2010: 113-122). Issue visibility, based on scientific evidence, fosters awareness of the seriousness of environmental problems, which in turn facilitates cooperation. The distribution of regulatory obligations matters, because if developed countries have already made substantial policy efforts and technological progress vis-à-vis developing countries, it would be easier for all countries involved to reach an agreement. Finally, lowering technological and economic costs incurred from switching to alternative substances would make countries less resistant to regulation.

Second, I assess how countries dealt with uncertainty over the consequences of institutional choices. Owing to difficulty in objectively analyzing the extent to which negotiating countries knew about institutional consequences, I analyze both countries' knowledge based on the availability of information on these ramifications and their utilization of such information to support their positions. More specifically, I identify the kinds of documents on existing treaties prepared by UNEP and then analyze how the contents of those documents influenced proposals and suggestions made by countries to the negotiations. If I find either of the two variables representing the severity of distributional problems and the extent of informational uncertainty, to differ between the two, I then assess how that variable can account for the observed institutional difference between the two treaties.

\section{Empirical Analysis}

\subsection{Outcomes of the Negotiations}

The mercury and POPs negotiations faced similar conflicts over the financial and compliance mechanisms. Regarding a financial mechanism, developing countries supported a new independent fund, while developing countries supported existing funds such as the GEF (UNEP 1999; UNEP 2010c: 10). ${ }^{6}$ In terms of a compliance mechanism, developed countries backed it

\footnotetext{
${ }^{6}$ Since the 1990s, developing countries have sharpened their criticism of the GEF for its bias toward donor nations and cumbersome application procedures (the author's interview with the UNEP International Environmental Technology Centre [IETC] official, who was a former delegate to the negotiations for the Minamata Convention on October 7, 2016).
} 
while developing countries opposed it. ${ }^{7}$ Despite the same contentions over both mechanisms, the resulting institutional outcomes were different.

\subsubsection{The Minamata Convention}

At the $25^{\text {th }}$ session of the UNEP Governing Council/Global Ministerial Environment Forum (GC-25/GMEF) in February 2009, countries agreed to establish a legally binding instrument on mercury. The Intergovernmental Negotiating Committee (INC) met five times from 2010 to 2013 and negotiated a draft treaty text. At INC5 (in 2013), countries agreed on a compliance and a financial mechanism. Both developing and developed countries engaged in reciprocal concessions. At an early stage of INC5, both sides agreed to form the "Implementation and Compliance Committee" (ICC) (Earth Negotiations Bulletin [ENB] 2013: 16-17). Despite their initial opposition to a compliance mechanism, developing countries accepted it because they inferred from progress in informal meetings that their developed counterparts were ready to concede on the financial mechanism later at INC5. ${ }^{8}$ Satisfied with a well-structured compliance mechanism, developed countries in turn agreed to create an independent fund. They found it a good strategy to consent to a financial mechanism that would make the compliance mechanism more functional. ${ }^{9}$ Then, both sides agreed on a GEF-plus package including three financial funds: (1) the Specific International Program (SIP); (2) the GEF; and (3) the Special Program (ENB 2013: 15-16). The SIP, a variant of an independent fund, was modeled after the ozone national units, a core component of the MLF under the MP (ENB 2013: 24). ${ }^{10}$ The foundation of the SIP as an independent fund, is regarded as a remarkable step in the history of environmental treaties.

\subsubsection{The Stockholm Convention}

The SC was negotiated in five steps from 1998 to 2000. Neither an independent fund nor a compliance mechanism was established by the convention. Instead, negotiators compromised on a tentative agreement for both. During the last negotiation stage of INC5, delegates considered a compliance mechanism and agreed on a compromise draft text containing an enabling clause suggested by the chair. The clause included a supplementary provision stating that "the COP shall, as soon as practicable, develop and approve procedures and institutional mechanisms for determining non-compliance with the provisions of the Convention and for the treatment of Parties found to be in non-compliance" (ENB 2000b: 12). As for a financial mechanism, countries finally agreed on a quasi-enabling clause that established the GEF as an "interim" financial mechanism until an independent fund was created at a future meeting (ENB 2000b: 1112). During the POPs negotiations, reciprocal concessions were never made because initial disagreements over both mechanisms remained unresolved throughout the process. This raises a question: Why were reciprocal concessions made in the mercury negotiations but not in the POPs

\footnotetext{
${ }^{7}$ See Note 2.

${ }^{8}$ The author's interview with a former Deputy Director of UNEP's Law Division, Mr. Nagai (Nairobi, July 17, 2017).

${ }^{9}$ See Note 2.

${ }^{10}$ The Special Program, a temporary financial mechanism of capacity building for least-developing countries, was meant to offset the GEF's deficiency.
} 
negotiations? In the following section, I will identify a factor observed only in the mercury negotiations that led to reciprocal concessions.

\subsection{Distributional Problems}

As argued in the theory section, we can explain distinct institutional outcomes by the different levels of distributional problems. In this section, I will explore whether the levels of distributional problems differed between the two conventions. The intensity of the distributional problems is measured by such issue-specific factors as issue visibility, the obligations of developed and developing countries, and the technological and economic costs of regulation. My analysis indicates that the intensity of a distributional problem is equally moderate.

\subsubsection{Issue visibility}

Regarding the MC, prior to the onset of the mercury negotiations, countries received the UNEP global mercury assessment (UNEP Chemicals and Inter-Organization Programme for the Sound Management of Chemicals [IOPSMC] 2002: Paragraph 139), which contains solid scientific evidence on the dangers of mercury. The report includes data on mercury exposure levels across regions (UNEP Chemicals and IOPSMC 2002: Paragraph 336). Having recognized this danger, countries shared a need for international action to reduce or eliminate mercury use. ${ }^{11}$

Likewise, regarding the SC, solid scientific evidence exists based on the toxicity of the "dirty dozen" POPs initially regulated by the treaty, including intentionally produced pesticides, dioxins, polychlorinated biphenyls (PCBs), and furans. Negotiators agreed to regulate most of these substances with relative ease, based on solid evidence (Yoder 2003: 141). Indeed, the final agreement on POPs was strongly supported by a variety of stakeholders, including government and public health officials, policymakers, and representatives from both environmental groups and the chemical industry - an extraordinary feat in the history of environmental treaties (Yoder 2003: 148).

\subsubsection{Obligations}

For the MC, the UNEP mercury assessment report indicated that while the use of mercury in developed countries has declined over recent decades, the use of mercury and mercury technologies is increasing across many developing countries (UNEP Chemicals and IOPSMC 2002: Paragraph 14). Developed countries have engaged in national and regional efforts to phase out the use of mercury in manufactured goods (e.g., thermometers) and in industrial processes (e.g., the chlor-alkali industry) by developing alternative technological methods (UNEP Chemicals and IOPSMC 2002: Paragraphs 728-793). Thus, the mercury problem was regarded as a matter of developing countries lacking safe alternative substances and disposal techniques. Due to technological progress, alternative substances and techniques have become available and will be transferred to developing countries by establishing a financial mechanism for licensing and training (UNEP Chemicals and IOPSMC 2002: Paragraph 14).

The interest structure of POPs was also similar to that of mercury. Many developed countries, including the European Union (EU) and the US, have already taken considerable policy measures

${ }^{11}$ The author's interview with UNEP officials during the COP1 meetings of the Minamata Convention (Geneva, September 2017). See Note 2. 
to regulate or phase out POPs. The US had implemented domestic measures regulating POPs and was fully prepared to regulate the "dirty dozen" before the POPs negotiation started (Schafer 2002: 171). Developed countries found it important to include in the treaty the developing countries that utilize POPs extensively as pesticides and for other industrial and agricultural purposes (Ahlgren 2014: 5).

\subsubsection{Technological and economic costs}

For the MC, the industries that needed to be regulated were limited to sectors such as coalfired power plants, chlor-alkali plants, and the mining and manufacturing of gold (UNEP Chemicals and IOPSMC 2002: Paragraph 27). The regulatory costs associated with reducing mercury usage in these industries were sufficiently low. Commercial applications of POPs were limited to specific industries and agriculture, and alternative substances were available at reasonable costs (Yoder 2003). With respect to the regulatory costs of chemical substances targeted under the convention, Yoder (2003: 151) asserts that the SC is similar to the MP.

In sum, the above analysis shows that the intensity of distributional problems, measured by issue structure, was equally moderate between the two negotiations. The same level of distributional problems should have resulted in the same institutional outcomes for the two treaties if all else were held equal. Thus, the absence of an independent fund and a compliance mechanism in the SC suggests that other factors can explain the different institutional outcomes. In the next subsection, I examine the influence of informational uncertainty by holding the intensity of a distributional problem constant.

\subsection{Informational Uncertainty and Learning}

As hypothesized, how countries deal with uncertainty over consequences of institutional choices influences institutional outcomes. Thus, I analyze the availability of negotiations documents and other learning sources through which negotiating countries can learn about institutional consequences from existing treaties. I also explore how negotiating countries utilized such information to advance their positions, which actually changed negotiation processes and outcomes.

In the mercury negotiations, countries obtained information-rich documents because UNEP responded favorably to the negotiating countries' request for information on the institutional performance of existing treaties. At the ad hoc Open-Ended Working Group (OEWG) held in 2009 prior to the INC, several countries requested that the secretariat provide information on a variety of financial and compliance mechanisms. ${ }^{12}$ For example, some said it would be useful to have information on financial and technical assistance models (UNEP 2009: 10). One representative requested documents on compliance mechanisms and their relative effectiveness (UNEP 2009: 10). Expressing their strong support for the MC, the EU and Switzerland requested such information to improve the Convention's effectiveness and avoid repeating the fates of other chemicals treaties. ${ }^{13}$ In general, before intergovernmental negotiations begin, negotiating countries determine their own issue positions by carefully and thoroughly examining

\footnotetext{
${ }^{12}$ See Note 8.
}

${ }^{13}$ See Note 8. 
supplementary documents submitted by UNEP. ${ }^{14}$ Thus, throughout the mercury negotiations, UNEP documents had significant influence on the countries' positions and serves as viable sources of information, given that countries rarely made their own independent analyses of institutional options regarding financial assistance and compliance. ${ }^{15}$

Representatives of the mercury negotiations who also participated in the annual COP meetings of other chemicals treaties requested the documents. Co-representation was a result of coordination between the chemicals treaties. Aiming at improving the efficiency of implementing the three chemicals-related treaties, the secretariats of the Basel, Rotterdam, and Stockholm Conventions (the "BRS secretariats") coordinated administrative activities such as national reporting and integrated individual COP meetings into "Triple COPs" in 2010. ${ }^{16}$ Due to this integration, the MC has been embedded in the family of chemicals treaties. ${ }^{17}$ Participating in all chemicals COPs, representatives became aware that even after the treaties took effect, the financial mechanisms remained weak and the enabling clause never turned into a compliance mechanism. Frustrated with these problems, they urged UNEP to improve the role of information and provide a detailed analysis of both mechanisms in the treaties. ${ }^{18}$ As a consequence, representatives in the mercury negotiations learned from the negotiations of existing treaties through UNEP documents, participation in the chemicals COPs, or both.

In the SC, however, countries did not request that UNEP provide documents before the INC began. ${ }^{19}$ Developed and developing countries were both optimistic that the environmental treaties agreed thus far would perform fairly well and did not find it necessary to acquire new data to improve the treaties. Hence, few new UNEP documents were submitted to the POPs negotiations. Regarding the financial mechanism, the documents provided by UNEP were limited in terms of volume and quality. UNEP merely provided one document listing the types of financial mechanisms adopted by existing environmental treaties but lacking comparative analyses (UNEP 1998a, 1998b). As for a compliance mechanism, UNEP did not prepare a single document. In 1998 when the POPs negotiations began, the available information on both financial and compliance mechanisms was limited to that on the MP and the Basel Convention on the Control of Transboundary Movements of Hazardous Wastes and Their Disposal (hereafter the Basel Convention). As shown below, such an informational shortage generated optimism among the negotiators on the interim GEF and an enabling clause.

\subsection{Influence on negotiation dynamics}

Owing to the UNEP documents on institutional consequences, the mercury negotiators learned about (1) functional linkage between financial and compliance mechanisms, (2) the dearth of financial mechanisms in chemicals treaties, and (3) the lack of an enabling clause for a compliance mechanism. In the following, I explore how each informational element changed the

\footnotetext{
${ }^{14}$ See Note 6.

15 See Note 8.

${ }^{16} \mathrm{http} / / / \mathrm{www}$.brsmeas.org, last accessed on July 20, 2017.

${ }^{17}$ Representatives for chemicals treaties, including the MC, are different from those for other issues, such as climate change. See Notes 11 and 8.

${ }^{18}$ See Note 8 .

19 The MC exceptionally set the stage for the pre-meeting, which gave countries opportunities to request information proactively. See Note 8 .
} 
negotiation dynamics, leading to reciprocal concessions during the subsequent phases of the mercury negotiations but not during the POPs negotiations.

\subsubsection{Information on functional linkage}

First, the documents related to the financial mechanism provided a comparative analysis of the pros and cons of various financial mechanisms that had operated under existing treaties (UNEP 2010b; UNEP 2011b). Based on the experiences in other treaties, the documents guided which form of financial mechanism could operate more effectively with a compliance mechanism. The documents indicated that an independent fund (e.g., the MLF, originally developed to enhance parties' compliance) could ensure functional linkage with a compliance mechanism more easily than the GEF to promote parties' implementation activities (UNEP 2010b: 10; UNEP 2011b: 1213; UNEP 2010a: 12-13). For example, while the GEF for the SC was aimed at promoting implementation activities that are not directly related to compliance, the MLF for the MP specified its funding scope to compliance-related projects and successfully improved compliance (UNEP 2011b: 12-13). Furthermore, voluntary trust funds such as those established for the Basel and Rotterdam Conventions are smaller and more difficult to handle for compliance purposes (UNEP 2010a: 13). In addition, the document recommended that representatives in the INC consider the possibility of negotiating and agreeing upon compliance and financial provisions of the mercury instrument as a package, rather than deal with them separately (UNEP 2010a: 13). This information led countries to realize the importance of functional linkage between compliance and financial mechanisms during the negotiations, as evident in their statements.

With the above information, countries became increasingly aware that both mechanisms together would serve their interests. Already in INC1, many countries requested linking discussions between the two (UNEP 2010c: 10-11; ENB 2010: 5, 12). For example, several countries emphasized the importance of functionally ensuring the linkage between compliance and financial mechanisms from the beginning (UNEP 2010c: 11). Unexpectedly, the African Group stressed functional linkage between compliance and financial mechanisms, stating that it would accept a compliance mechanism insofar as the mechanism was coordinated closely with funding and technology transfer (ENB 2010: 5). Recognizing a strong functional link between financial assistance and compliance, several representatives suggested that the establishment of a financial mechanism be accompanied by a compliance mechanism (UNEP 2011a: 25).

Learning about functional linkage between the two mechanisms from the UNEP documents, countries viewed the mechanisms not as separate but rather as integral institutions. Both developed and developing countries noticed that functional linkage would produce a positive synergy, which would result in reciprocal concessions in subsequent negotiations. On the other hand, in the POPs negotiations no information was presented on the functional linkage; therefore, two mechanisms were negotiated as completely separate agendas as indicated below.

\subsubsection{Information on the financial mechanism}

Second, representatives learned from a financial discussion developed in chemicals COPs. An integrated financial approach across chemicals treaties was initiated in the negotiations of COP4 for the SC, based on recognition of the need for adequate resources in the field of chemicals and 
waste management. ${ }^{20}$ Then-executive director Achim Steiner led an initiative to enhance the effectiveness of chemicals treaties by reducing the problem of underfunding. ${ }^{21}$ Countries acknowledged financial scarcity as a significant problem underlying the family of chemicals treaties that had either a voluntary fund or the interim GEF as their financial mechanism. During the mercury negotiation, developing countries cited the insufficiency of financial provisions as a reason for an independent fund to be created in the MC.

Learning from chemicals COPs, however, countries recognized the limitations of the GEF and acknowledged the virtue of an independent fund - a more appealing option for developed and developing countries alike. At the beginning of negotiations, developed countries supported the GEF, while developing nations backed an independent fund. Developing countries strongly requested an independent fund, stressing that the financial provisions in the chemical treaties were insufficient. The African Group requested the foundation of an adequately financed independent fund on mercury to be governed by the COP for transparency, accessibility, equality, and responsiveness to their needs (ENB 2010: 5). As stated above, the African Group said it would accept a compliance mechanism once its request for independent funds was met. The EU, Norway, and Switzerland, albeit initially having favored the GEF, admitted that it was not an effective capacity-building measure (ENB 2010: 11). In addition, several developed countries implied their intention to approve an independent fund. While viewing the GEF as their preferred option, the EU countries, Switzerland, and Canada stated that they were open to the idea of a multilateral fund (i.e., an independent fund) (ENB 2011a: 9). One representative argued that the MLF was key to the success of the MP, as it provided developing countries with funds for implementation and compliance (UNEP 2011c: 20). They changed their positions based on recognition of the GEF's limitations and the relative effectiveness of an independent fund in capacity building. Thus, developed countries became willing to consider creating an independent fund along with the GEF (UNEP 2012: 18). Such a conciliatory attitude led developing countries to strengthen their position on an independent fund and concede on a compliance mechanism (UNEP 2010c: 10).

In the POPs negotiations, there was one document on financial options prepared for INC2. However, it only listed types of financial mechanisms adopted by existing environmental treaties and did not provide a detailed analysis on the financial mechanisms. The conflict between an independent fund and the GEF surfaced in INC2, and never eased throughout the remaining negotiations. Several representatives suggested a third proposal of combining an independent fund and the GEF in INC4 (UNEP 2000: 16), but this proposal was not included into the draft text, unlike the mercury negotiations (ENB 1998, 1999a, 1999b, 2000a, 2000b). Based on limited experiences with the voluntary fund of the Basel Convention, countries probably believed that an interim GEF as a compromise would be more robust than a voluntary fund. However, the former later turned out to be as fragile as the latter.

\subsubsection{Information on the compliance mechanism}

\footnotetext{
${ }^{20}$ This point was extracted from the Basel, Rotterdam, and Stockholm Conventions website http://www.brsmeas.org/Implementation/ResourceMobilization/ConsultativeProcessonFinancingOptions/ta bid/2880/language/es-CO/Default.aspx (last accessed on July 20, 2017).

${ }^{21}$ See Note 2.
} 
Regarding the compliance mechanism, countries learned about the institutional consequences directly from chemicals COPs as well as from UNEP documents. As mentioned above, representatives failed to reach an agreement to make the enabling clause into a compliance mechanism for the Rotterdam and Stockholm Conventions. ${ }^{22}$ In addition, one UNEP document on a compliance mechanism stressed the difficulties facing chemicals treaties (UNEP 2010a). It showed that an enabling clause was used to obtain agreement for the conclusion of a treaty when parties could not settle their divisive opinions on a compliance mechanism within a negotiations timetable. The enabling clause has not become a compliance mechanism in COPs to date because of the political difficulties associated with renegotiations. Neither the Rotterdam nor the Stockholm Convention has established compliance procedures, although both include enabling clauses (UNEP 2010a: 14).

Recognizing the shortcoming of an enabling clause, both parties increased support for a compliance mechanism. At the beginning of the negotiations, developed countries preferred a compliance mechanism equipped with a compliance committee within the treaty text, while developing countries preferred an enabling clause that would become a compliance mechanism at an appropriate time after the treaty entered into force (UNEP 2010c: 10). The EU, Switzerland, Norway, and Canada highlighted the importance of a compliance mechanism with a compliance committee to be established upon the conclusion of a treaty. They suggested that both the Rotterdam and the Stockholm Conventions failed to create compliance procedures despite the adoption of enabling clauses (ENB 2010: 12). However, to obtain a compliance mechanism, the EU, the US, Japan, Canada, Norway, and the African Group proposed to establish a committee in the treaty text that would encompass "implementation" and/or "compliance" (ENB 2011a: 9). This was because developed countries predicted that an "implementation" committee would be more acceptable for developing countries than a compliance committee with a nuance of political intervention (ENB 2011a: 13). In reaction to the proposal, developing countries other than the African Group renounced an enabling clause option, allowing convergence into a "within-thetreaty-text" option for a compliance mechanism. This was also aimed at inducing concessions by developed countries over an independent fund (ENB 2011b: 13). Such moves led to a successful agreement on creating a compliance mechanism in the last INC5.

In sum, upon learning about the shortcoming of an enabling clause, developing countries chose to accept a compliance mechanism to obtain an independent fund. Likewise, after learning about the difficulty of establishing compliance mechanisms within the chemical treaties, developed countries strengthened their claim on compliance in the mercury treaty text to avoid repeating the failures of the chemical treaties. Both sides reciprocated concessions, contributing to the formation of a trinity.

In the POPs negotiations, no informational document on a compliance mechanism was prepared by the UNEP. Already in INC2, many representatives claimed that a compliance mechanism should be created to determine non-compliance and to assist non-compliant parties in securing compliance (UNEP 1999). However, developing countries opposed a compliance mechanism. Nonetheless, developed countries did not strongly demand the establishment of a compliance mechanism for the rest of the POPs negotiations, while they did so in the mercury negotiations (ENB 1999a, 1999b). Thus, a compliance clause was not seriously discussed before

${ }^{22}$ See Note 11. 
an enabling clause was adopted as a compromise due to a shortage of time (ENB 2000a). The MP had an effective mechanism formed several years after its adoption, despite its lack of an enabling clause in its original treaty text. ${ }^{23}$ In this regard, an enabling clause within the SC was regarded as a major step achieved upon conclusion. Moreover, this was right before the Basel Convention converted an enabling clause into an actual compliance mechanism in 2002. Having observed these developments, countries believed that an enabling clause could be easily turned into a compliance mechanism. Furthermore, the Rotterdam Convention had just adopted an enabling clause in 1998. These suggest that the institutional consequences of an enabling clause were still unknown at the time and over-evaluated due to limited learning sources. Thus, negotiating countries of the POPs found it convenient to postpone a substantive discussion by adopting an enabling clause as a temporary measure.

The analyses of the mercury and POPs negotiations can be summarized as follows. Having learned from UNEP documents as well as chemicals COPs meetings, negotiating countries of the MC benefited from abundant sources of information, while those of the SC did not. The negotiators for the MC observed the variable consequences of both compliance and financial mechanisms in the chemical treaties, including the SC, providing an impetus to create a trinity. The above explanation can be contrasted with alternative interpretations deriving from rival theories of international relations. First, the hegemonic stability theory posits that the successful adoption of a trinity in Minamata is attributable to hegemonic leadership therein, whereas the failure of Stockholm owes to hegemonic absence. Contrary to the realist prediction, the EU played a leadership role in establishing effective treaties in both negotiations, bearing fruits in the former but not in the latter. ${ }^{24}$ Second, constructivist theory predicts that epistemic communities should obtain a consensus on the scientific assessment of mercury's toxicity for strong institutions (i.e., an independent fund and a compliance mechanism), whereas they should have ambivalent assessment of the toxicity of POPs regulated by Stockholm for weak ones. Again, constructivism is rejected in light of the fact that epistemic communities held consensual evaluations on the toxicity of both mercury and the POPs, as demonstrated in Section 4.2.1.

\section{Conclusion: Incremental learning and mimetic diffusion}

In this paper, I have asked why countries agreed to establish both an independent fund and a compliance mechanism in the MC but not in the SC. To answer this question, I examined two factors: (1) the severity of distributional problems and (2) how countries dealt with informational uncertainty about institutional consequences. I found that distributional problems were moderate for both the Mercury and Stockholm Conventions. On the other hand, countries dealt with uncertainty better in the Minamata negotiations than in the Stockholm negotiations because information on institutional consequences was abundant in the former but limited in the latter.

The comparative analysis supports $\mathrm{H} 2$ over $\mathrm{H} 1$, leading me to conclude that institutional diffusion theory can account for a trinity in the MC. Throughout the Stockholm negotiations, countries failed to establish an independent fund and a compliance mechanism, even though the distributional problem was as moderate as that of the MC. The absence of two mechanisms in the

${ }^{23}$ See Note 8.

${ }^{24}$ See Note 11. 
SC can be traced to the scarcity of information that resulted in limited and even incorrect understandings of institutional consequences. In relation to Templeton and Kohler (2014), this paper reveals that issue linkage - critical to the Minamata agreement - was ensured because negotiating counties learned from existing treaties. Furthermore, the paper provides evidence for mimetic diffusion and incremental learning (Boerner et al. 2001: 92, 104, Ovodenko and Keohane 2012). As for the POPs negotiations, treaty experience was limited, and information was not processed appropriately to predict institutional consequences. Faced with high uncertainty, countries appeared to engage in mimetic diffusion by adopting existing institutions believed to be successful. However, for the MC, treaty experience was accumulated over a decade and effectively processed by negotiators to reduce uncertainty.

However, even if incremental learning evolves along with informational intermediation, negotiating countries may not be able to reach an agreement on a suitable institutional design when an underlying distributional problem is too severe like climate change. In this respect, my findings are not generalizable because they rest on a set of treaties with moderate distributional problems. Nonetheless, both the POPs and mercury negotiations were characterized by conflicting interests, which were overcome by reducing informational uncertainty. My findings shed light on the importance of analyzing informational uncertainty as a determinant of institutional outcomes. Future research should explore the influence of informational uncertainty under different levels of distributional problems.

\section{References}

Alchian, A. A. (1950). Uncertainty, evolution, and economic theory. Journal of Political Economy, 58(3), 211-221.

Abbott, K. W., \& Snidal, D. (2000). Hard and Soft Law in International Governance. International Organization, 54 (3), 421-456.

Ahlgren, C. (2014). Future Challenges to the Stockholm Convention on Persistent Organic Pollutants. Bachelor Thesis $15 \mathrm{hp}$, Lund University.

Andresen, S., Rosendal, K., \& Skjærseth, J. B. (2013). Why negotiate a legally binding mercury convention?. International Environmental Agreements: Politics, Law and Economics, 13(4), 425440 .

Boerner, C. S., Macher, J. T., \& Teece, D. J. (2001). A review and assessment of organizational learning in economic theories. In Dierkes, M., Antal, A. B., Child, J., \& Nonaka, I. (Eds.), Handbook of Organizational Learning and Knowledge (Chapter 4). Oxford University Press, USA.

Brunnée, J. (2006). Enforcement Mechanisms in International Law and International Environmental law. In Ulrich Beyerlin, Peter-Tobias Stoll, and Rüdiger Wolfrum (Eds.), 
Ensuring Compliance with Multilateral Environmental Agreements: A Dialogue between Practitioners and Academia (pp.1-24). Brill.

De Chazournes, L. B. (2006). Technical and Financial Assistance and Compliance: The Interplay. In Ulrich Beyerlin, Peter-Tobias Stoll, \& Rüdiger Wolfrum (Eds.), Ensuring Compliance with Multilateral Environmental Agreements: A Dialogue between Practitioners and Academia (pp. 273-300). Brill.

Earth Negotiations Bulletin. (1998). Report of the First Session of INC for an International Legally Binding Instrument for Implementing International Action on Certain Persistent Organic Pollutants (POPS): 29 June-3 July 1998. International Institute for Sustainable Development.

Earth Negotiations Bulletin. (1999a). The Second Session of the International Negotiating Committee for an International Legally Binding Instrument for Implementing International Action on Certain Persistent Organic Pollutants (POPS): 25-29 January 1999. International Institute for Sustainable Development.

Earth Negotiations Bulletin. (1999b). Summary of the Third Session of the International Negotiating Committee for an International Legally Binding Instrument for Implementing International Action on Certain Persistent Organic Pollutants (POPS): 6-11 September 1999. International Institute for Sustainable Development.

Earth Negotiations Bulletin. (2000a). Summary of the Fourth Session of the International Negotiating Committee for an International Legally Binding Instrument for Implementing International Action on Certain Persistent Organic Pollutants (POPS): 20-25 March 2000. International Institute for Sustainable Development.

Earth Negotiations Bulletin (2000b). Summary of the Fifth Session of the International Negotiating Committee for an International Legally Binding Instrument for Implementing International Action on Certain Persistent Organic Pollutants (POPS): 4-9 December 2000. International Institute for Sustainable Development.

Earth Negotiations Bulletin. (2010). First Meeting of the Intergovernmental Negotiation Committee to Prepare a Global Legally Instrument on Mercury: 7-11 June 2010. International Institute for Sustainable Development.

Earth Negotiations Bulletin. (2011a). Summary of the Second Meeting of the Intergovernmental Negotiation Committee to Prepare a Global Legally Instrument on Mercury: 24-28 January 2011. International Institute for Sustainable Development.

Earth Negotiations Bulletin. (2011b). Summary of the Third Meeting of the Intergovernmental Negotiation Committee to Prepare a Global Legally Instrument on Mercury: 31 October - 4 November 2011. International Institute for Sustainable Development. 
Earth Negotiations Bulletin. (2013). Summary of the Fifth Session of the Intergovernmental Negotiating Committee to Prepare a Global Legally Binding Instrument on Mercury: 13-19 January 2013. International Institute for Sustainable Development.

Eriksen, H. H., \& Perrez, F. X. (2014). The Minamata Convention: A Comprehensive Response to a Global Problem. Review of European, Comparative \& International Environmental Law, 23(2), 195-210.

Koremenos, B., Lipson, C., \& Snidal, D. (2001). The Rational Design of International Institutions. International Organization, 55 (4), 761-799.

Marcoux, C., Peeters, C. \& Tierney, M. J. (2011). Principles or Principals? Institutional Reform and Aid Allocation in the Global Environment Facility (GEF). Unpublished paper presented in the Political Economy of International Organizations Conference.

Marsh, D., \& Sharman, J.C. (2009). "Policy Diffusion and Policy Transfer.” Policy Studies, 30(3), 269-288.

Mitchell, R. B. (1994). Regime Design Matters: Intentional Oil Pollution and Treaty Compliance. International Organization, 48 (3), 425-458.

Mitchell, R. B. (2007). Compliance theory: compliance, effectiveness, and behaviour change in international environmental law. In Brunnée J., Bodansky, D., and Hey, E. (Eds.), Oxford Handbook of International Environmental Law (pp. 893-921), Oxford University Press.

Mitchell, R. B. (2010). International Politics and the Environment. Sage Publications.

Mitchell, R. B., \& Keilbach, P.M. (2001). Situation Structure and Institutional Design:

Reciprocity, Coercion, and Exchange. International Organization, 55 (4), 891-917.

Ovodenko, A., \& Keohane, R.O. (2012). Institutional Diffusion in International Environmental Affairs. International Affairs, 88(3), 523-541.

Raustiala, K. (2001). Reporting and Review Institutions in 10 Selected Multilateral Environmental Agreements. UNEP, Nairobi.

Schafer, K. (2002). Ratifying Global Toxics Treaties: The US Must Provide Leadership. SAIS Review, 22(1), 169-176.

Selin, H. (2014). Global Environmental Law and Treaty-Making on Hazardous Substances: The Minamata Convention and Mercury Abatement. Global Environmental Politics, 14(1), 1-19. 
Selin, N. E., \& Selin, H. (2006). Global Politics of Mercury Pollution: The Need for Multi-Scale Governance. Review of European Community \& International Environmental Law, 15(3), 258269.

Simmons, B. A., Dobbin, F., \& Garrett, G. (2006). Introduction: The international diffusion of liberalism. International Organization, 60(4), 781-810.

Simon, H. A. (1957). Models of man; social and rational.

Stokes, L. C., Giang, A., \& Selin, N. E. (2016). Splitting the South: Explaining China and India's Divergence in International Environmental Negotiations. Global Environmental Politics, 16(4), 12-31.

Streck, C. (2001). The Global Environment Facility -a Role Model for International Governance? Global Environmental Politics, 1(2), 71-94.

Sun, Y. (2017). Transnational Public-Private Partnerships as Learning Facilitators: Global Governance of Mercury. Global Environmental Politics, 17(2), 21-44.

Templeton, J., \& Kohler, P. (2014). Implementation and Compliance under the Minamata Convention on Mercury. Review of European, Comparative and International Environmental Law, 23(2), 211-220.

Thompson, A. (2010). Rational Design in Motion: Uncertainty and Flexibility in the Global Climate Regime. European journal of international relations, 16(2), 269-296.

UNEP. (1998a). Existing mechanisms for providing technical and financial assistance to developing countries and countries with economies in transition for environmental projects: Executive summary. UNEP/POPS/INC.2/4. UNEP.

UNEP. (1998b). Existing mechanisms for providing technical and financial assistance to developing countries and countries with economies in transition for environmental projects. UNEP/POPS/INC.2/INF/4. UNEP.

UNEP. (1999). Report of the International Negotiating Committee for an International Legally Binding Instrument for Implementing International Action on Certain Persistent Organic Pollutants on the Work of its Second Session. UNEP/POPS/INC.2/6. UNEP.

UNEP. (2000). Report of the International Negotiating Committee for an International Legally Binding Instrument for Implementing International Action on Certain Persistent Organic Pollutants on the Work of its Fourth Session. UNEP/POPS/INC.4/5. UNEP.

UNEP. (2007). Study on Options for Global Control of Mercury. UNEP(DTIE)/Hg/OEWG.1/2. UNEP. 
UNEP. (2009). Report of the Ad Hoc Open-ended Working Group to Prepare for the Intergovernmental Negotiating Committee on Mercury. UNEP(DTIE)/Hg/WG.Prep/1/10. UNEP.

UNEP. (2010a). Key Concepts, Procedures and Mechanisms of Legally Binding Multilateral Agreements that May be Relevant to Furthering Compliance under the Future Mercury Instrument Concept on Compliance. UNEP (DTIE)/Hg/INC.1/11. UNEP.

UNEP. (2010b). Options for Predictable and Efficient Financial Assistance Arrangements. UNEP (DTIE)/Hg/INC.1/8. UNEP.

UNEP. (2010c). Report of the Intergovernmental Negotiating Committee to Prepare a Global Legally Binding Instrument on Mercury on the Work of its First Session. UNEP (DTIE)/Hg/INC.1/21. UNEP.

UNEP. (2011a). Report of the Intergovernmental Negotiating Committee to Prepare a Global Legally Binding Instrument on Mercury on the Work of its Second Session. UNEP (DTIE)/Hg/INC.2/20. UNEP.

UNEP. (2011b). Further Comparative Analysis of Options for Financial Mechanisms to Support the Global Legally Binding Instrument on Mercury. UNEP (DTIE)/Hg/INC.3/4. UNEP.

UNEP (2011c). Report of the Intergovernmental Negotiating Committee to Prepare a Global Legally Binding Instrument on Mercury on the Work of its Third Session. UNEP (DTIE)/Hg/INC.3/8. UNEP.

UNEP. (2012). Report of the Intergovernmental Negotiating Committee to Prepare a Global Legally Binding Instrument on Mercury on the Work of its Fourth Session. UNEP (DTIE)/Hg/INC.4/8. UNEP.

UNEP Chemicals and Inter-Organization Programme for the Sound Management of Chemicals. (2002). Global mercury assessment. UNEP Chemicals.

Victor, D. G. (1999). Enforcing International Law: Implications for an Effective Global Warming Regime. Duke Environmental Law and Policy Forum, (10), 147-184.

Weyland, K. (2005). Theories of policy diffusion: lessons from Latin American pension reform. World Politics, 57 (January), 262-295.

Yoder, A. J. (2003). Lessons from Stockholm: evaluating the global convention on persistent organic pollutants. Indiana Journal of Global Legal Studies, 10(2), 113-156. 